\title{
GAMBARAN KEJADIAN ASFIKSIA DI UPTD PUSKESMAS AJANGALE PADA TAHUN 2016/2017
}

\author{
Arfan nur \\ AKBID Bina Sehat Nusantara Bone \\ Alamat korespondensi : (arfan.nur2309@gmail.com/085399355143)
}

\begin{abstract}
ABSTRAK
Asfiksia pada bayi baru lahir termasuk risiko tinggi karena memiliki kemungkinan lebih besar mengalami kematian bayi atau menjadi sakit berat dalam masa neonatal. Di Indonesia mempunyai 200 juta penduduk dengan angka kelahiran 2,5\% tahun sehingga diperkirakan terdapat 5 juta kelahiran per tahun. Untuk mengetahui gambaran kejadian Asfiksia berdasarkan faktor resiko ibu, bayi dan faktor persalinan di UPTD Puskesmas Ajangale. Penelitian ini dilakukan secara deskriptif dengan menggunakan data sekunder di UPTD Puskesmas Ajangale untuk mengetahui gambaran umum kejadian asfiksia pada bayi baru lahir dengan variabel-variabel penelitian yang meliputi faktor risiko ibu, bayi dan persalinan. Dari 389 responden, bayi baru lahir yang mengalami asfiksia pada tahun 2016 sebesar 3,08\%, sedangkan pada tahun 2017 dari 374 responden sebesar 5,61\%. Berdasarkan faktor risiko bayi tahun 2016 dengan faktor risiko rendah sebesar 83,33\%, tahun 2017 dengan faktor risiko rendah sebesar 76,19\%. Faktor risiko ibu pada tahun 2016 dengan risiko tinggi sebesar $41,67 \%$, tahun 2017 dengan risiko tinggi sebesar 52,38\%. Faktor persalinan pada tahun 2016 dengan lilitan tali pusat sebesar 16,67\%, tahun 2017 dengan lilitan tali pusat sebesar 28,57\%.Faktor yang berhubungan dengan kejadian asfiksia di UPTD Puskesmas Ajangale di pengaruhi oleh faktor risiko ibu, bayi dan persalinan.
\end{abstract}

\section{Kata Kunci : Asfiksia, bayi, persalinan, lilitan tali pusat, Umur, paritas, pendidikan, pekerjaan}

\section{PENDAHULUAN}

Asfiksia pada bayi baru lahir termasuk risiko tinggi karena memiliki kemungkinan lebih besar mengalami kematian bayi atau menjadi sakit berat dalam masa neonatal. Oleh karena itu asfiksia memerlukan intervensi dan tindakan yang tepat untuk meminimalkan terjadinya kematian bayi, yaitu dengan pelaksanaan manajemen asfiksia pada bayi baru lahir yang bertujuan untuk mempertahankan kelangsungan hidup bayi dan membatasi gejala sisa berupa kelainan neurologi yang mungkin muncul, dengan kegiatan yang difokuskan pada persiapan resusitasi, keputusan resusitasi bayi baru lahir, tindakan resusitasi, asuhan pasca resusitasi, asuhan tindak lanjut pasca resusitasi dan pencegahan infeksi (Depkes. RI, 2008).

World Health Organisation (WHO) menyatakan bahwa pada tahun 2013 Angka Kematian Bayi (AKB) di dunia 34 per 1000 kelahiran hidup dan mengalami peningkatan pada tahun 2015 dengan Angka Kematian Bayi (AKB) 43 per 1000 kelahiran hidup. Di kawasan Asia Teggara, AKB 24 per 1000 kelahiran hidup (WHO.2016).

Pada tahun 2012 Kementerian Kesehatan meluncurkan program Expanding Maternal and Neonatal Survival (EMAS) dalam rangka menurunkan angka kematian ibu dan neonatal sebesar $25 \%$. Program ini dilaksanakan di provinsi dan kabupaten dengan jumlah kematian ibu dan neonatal yang besar, yaitu Sumatera Utara, Banten, Jawa Barat, Jawa Tengah, Jawa Timur, dan Sulawesi Selatan. Dasar pemilihan provinsi tersebut disebabkan $52,6 \%$ dari jumlah total kejadian kematian ibu di Indonesia berasal dari enam provinsi tersebut. Sehingga dengan menurunkan angka kematian ibu di enam provinsi tersebut diharapkan akan dapat menurunkan angka kematian ibu di Indonesia secara signifikan.

Angka kematian neonatal (AKN) usia 0-28 hari menjadi penting karena kematian neonatal memberi kontribusi terhadap 59\% kematian bayi. Tingginya angka kematian di Indonesia yang merupakan masalah besar dan memerlukan perhatian, Angka Kematian Ibu menujukkan penurunan menjadi 305 kematian ibu per 100.000 kelahiran hidup berdasarkan hasil Survei Penduduk Antar Sensus (SUPAS) (Profil Kesehatan Indonesia, 2016).

Di Sulawesi Selatan, AKN menunjukkan sebesar 838 atau sebesar 5,64 per 1.000 kelahiran hidup. Jumlah kematian ibu tahun 2016 yang dilaporkan menjadi 153 orang atau 103,00 per 100.000 kelahiran hidup, terdiri dari 
kematian ibu hamil 47 orang $(30,71 \%)$, kematian ibu bersalin 44 orang $(27,45 \%)$, kematian ibu nifas 62 orang $(40,52 \%)$, adapun kematian ibu menurut umur yaitu $<20$ tahun sebanyak 7 orang, umur 20-34 tahun sebanyak 101 orang, dan $\geq 35$ tahun sebanyak 45 orang (Profil Kesehatan Sulawesi Selatan, 2016).

Berdasarkan data dari Dinas Kesehatan Kab. Bone Provinsi Sulawesi Selatan angka kematian neonatal tahun 2016 sebanyak 83 bayi dan tahun 201761 bayi, sedangkan yang mengalamai asfiksia tahun 2016 sebanyak 102 bayi dan mengalami peningkatan tahun 2017 sebanyak 131 bayi (Dinas Kesehatan Kabupaten Bone 2016-2017)

Depkes RI 2008 menyebutkan bahwa kehamilan yang terlalu muda ( $\leq 20$ tahun) atau terlalu tua ( $\geq 35$ tahun) termasuk dalam kriteria risiko tinggi kehamilan. Usia muda berisiko karena secara medis organ reproduksi ibu masih belum matang dan secara mental pun masih belum siap. Pada usia tua ( $\geq 35$ tahun) mempunyai predisposisi untuk mengalami plasenta previa, rupture uteri, solutio plasenta yang dapat berakhir dengan terjadinya asfiksia neonatorum (Depkes.RI 2008).

Studi pendahuluan yang peneliti lakukan di UPTD Puskemas Ajangale Kab. Bone, tahun 2016 kejadian Asfiksia terdapat 12 kasus dari 389 persalinan dan kejadian Asfiksia mengalami peningkatan pada tahun 2017 yaitu 21 kasus dari 374 persalinan.

Berdasarkan studi pendahuluan dan permasalahan, dimana banyak faktor yang menyebabkan terjadinya asfiksia neonaturum dan di UPTD Puskesmas Ajangale mengalami peningkatan kejadian asfiksia dari tahun 2016 ke tahun 2017 maka penulis tertarik untuk meneliti mengenai gambaran kejadian Asfiksia di UPTD Puskesmas Ajangale tahun 2016 2017 berdasarkan faktor resiko.

\section{BAHAN DAN METODE}

Lokasi, populasi dan sampel

Penelitian ini menggunakan metode deskriptif, Populasi dalam penelitian ini adalah semua bayi baru lahir di UPTD Puskesmas Ajangale Kab. Bone Tahun 2016 - 2017 yang berjumlah 763 bayi baru lahir.

Sampel dalam penelitian ini yaitu semua bayi yang mengalami asfiksia di UPTD Puskesmas Ajangale Kab. Bone Tahun 2016 2017 sebanyak 33 bayi asfiksia, yaitu 12 bayi pada tahun 2016 dan 21 bayi pada tahun 2017.

1. Kriteria Inklusi

Data bayi yang mengalami Asfiksia tahun 2016 dan 2017.
2. Kriteria Ekslusi

Data bayi dengan penyakit berbeda NonAsfiksia).

\section{Pengumpulan Data}

1. Data Sekunder

Data penelitian diperoleh dengan cara mengumpulkan data yang telah memenuhi kriteria pengambilan sampel (variabelvariabel penelitian yang telah terpenuhi atau lengkap) yang diambil dari data rekam medik dan dikelompokkan pada lembar isian penelitian untuk selanjutnya dilakukan analisa variabel penelitian.

2. Data Primer

Data yang dikumpulkan dan diolah sendiri oleh suatu organisasi atau perorangan langsung dari objeknya.

\section{Pengolahan Data}

1. Editing

Editing adalah tahapan kegiatan memeriksa validitas data yang masuk seperti memeriksa kelengkapan pengisian kuesioner, kejelasan jawaban, relevansi jawaban dan keseragaman suatu pengukuran.

2. Coding

Coding adalah tahapan kegiatan mengklasifikasi data dan jawaban menurut kategori masing-masing sehingga memudahkan dalam pengelompokan data.

3. Processing

Processing adalah tahapan kegiatan memproses data agar dapat dianalisis. Pemrosesan data dilakukan dengan cara memasukkan data hasil pengisian kuesioner ke dalam master tabel.

4. Cleaning

Cleaning yaitu tahapan kegiatan pengecekan kembali data yang sudah di masukkandan melakukan koreksi bila terdapat kesalahan. (Lapau, 2013).

\section{Analisa Data}

Analisa data univariat Yaitu analisa yang dilakukan terhadap tiap variabel dari hasil penelitian. Pada umumnya dalam analisa ini hanya menghasilkan distribusi dan presentasi dari tiap variabel karena penelitian ini ingin mengetahui distribusi frekuensi dan presentasi masing-masing variabel yang diteliti.

\section{HASIL PENELITIAN}

Berdasarkan hasil penelitian yang telah dilakukan di UPTD Puskesamas Ajangale Kabupaten Bone tahun 2018 dengan data sekunder tahun 2016/2017 tentang bayi baru lahir dengan asfiksia, dapat disimpulkan 
bahwa : Jumlah asfiksia sebanyak 33 kasus yang dilihat dengan beberapa faktor risiko seperti faktor bayi, faktor ibu dan faktor persalinan. Berdasarkan faktor risiko bayi, pada tahun 2016 terdapat 2 kasus dengan risiko tinggi sebesar $16,67 \%$, dan pada tahun 2017 terdapat 5 kasus dengan risiko tinggi sebesar $23,81 \%$.

1. Analisa Univariat

Tabel 1. Karakteristik responden berdasarkan kejadian asfiksia $(n=763)$

\begin{tabular}{|c|c|c|c|c|}
\hline \multirow{2}{*}{ Asfiksia } & \multicolumn{4}{|c|}{ Tahun } \\
\cline { 2 - 5 } & \multicolumn{2}{|c|}{2016} & \multicolumn{2}{c|}{2017} \\
\cline { 2 - 5 } & $\mathrm{n}$ & $\%$ & $\mathrm{n}$ & $\%$ \\
\hline Ya & 12 & 3,08 & 21 & 5,61 \\
\hline Tidak & 377 & 96,92 & 353 & 94,39 \\
\hline Total & 389 & 100 & 374 & 100 \\
\hline
\end{tabular}

Berdasarkan tabel 1. menunjukan karakteristik responden berdasrkan kejadian asfeksi pada tahun 2016 mencapai $3,08 \%$ dan yang tidak mengalami asfeksi sebesar 96,92\% sedangkan angka pada tahun 2017 angka kejadian yang mengalami asfeksia sebesar $5,61 \%$ dan yang tidak mengalami asfeksi sebesar $94,39 \%$.

Tabel 2 Karakteristik responden berdasarkan faktor risiko bayi.

\begin{tabular}{|c|c|c|c|c|}
\hline \multirow{2}{*}{$\begin{array}{c}\text { Faktor } \\
\text { Risiko Bayi }\end{array}$} & \multicolumn{4}{|c|}{ Tahun } \\
\cline { 2 - 5 } & \multicolumn{2}{|c|}{2016} & \multicolumn{2}{|c|}{2017} \\
\cline { 2 - 5 } & $\mathrm{n}$ & $\%$ & $\mathrm{n}$ & $\%$ \\
\hline Risiko rendah & 10 & 83,33 & 16 & 76,19 \\
\hline Risiko Tinggi & 2 & 16,67 & 5 & 23,81 \\
\hline Total & 12 & 100 & 21 & 100 \\
\hline
\end{tabular}

Berdasrkan tabel 2. menunjukan karakteristik responden berdarkan faktor resiko bayi resiko tinggi pada tahun 2016 sebesar $16,67 \%$ dan resiko rendah sebesar $83,33 \%$, sedangkan pada tahun 2017 angka karakteristik responden berdasrarkan faktor resiko bayi dengan angka faktor resiko tinggi sebesar $23,81 \%$ dan faktor resiko rendah $76,19 \%$.

Tabel 3. Karakteristik responden berdasarkan faktor risiko ibu.

\begin{tabular}{|c|c|c|c|c|}
\hline \multirow{2}{*}{ Faktor Risiko lbu } & \multicolumn{4}{|c|}{ Tahun } \\
\cline { 2 - 5 } & \multicolumn{2}{|c|}{2016} & \multicolumn{2}{|c|}{2017} \\
\cline { 2 - 5 } & $\mathrm{n}$ & $\%$ & $\mathrm{n}$ & $\%$ \\
\hline Risiko render & 7 & 58,33 & 11 & 52,38 \\
\hline Risiko Tinggi & 5 & 41,67 & 10 & 47,62 \\
\hline Total & 12 & 100 & 21 & 100 \\
\hline
\end{tabular}

Berdasarkan tabel 3. menunjukan karaktersitik responden berdasrkan faktor resiko ibu pafa tahun 2016 dengan resiko tinggi sebesar $41.67 \%$ dan resiko rendah sebesar 58,33\% sedangkan pada tahun 2017 angka resiko tinggi sebesar $47,62 \%$ dan angka resiko rendah sebesar 52,38\%.

Tabel 4. Karakteristik Responden Berdasarkan Faktor Risiko Persalinan.

\begin{tabular}{|c|c|c|c|c|}
\hline \multirow{2}{*}{$\begin{array}{c}\text { Faktor Risiko } \\
\text { Persalinan }\end{array}$} & \multicolumn{4}{|c|}{ Tahun } \\
\cline { 2 - 5 } & $\mathrm{n}$ & $\%$ & $\mathrm{n}$ & $\%$ \\
\hline $\begin{array}{c}\text { Tidak Lilitan } \\
\text { Tali Pusat }\end{array}$ & 10 & 83,33 & 15 & 71,43 \\
\hline $\begin{array}{c}\text { Lilitan Tali } \\
\text { Pusat }\end{array}$ & 2 & 16,67 & 6 & 28,57 \\
\hline Total & 12 & 100 & 21 & 100 \\
\hline
\end{tabular}

Berdasrkan tabel 4. Menunjukan faktor resiko persalinan pada tahun 2016 dengan lilitan tali pusat sebesar $16,67 \%$ dan tidak terlilit tali pusat sebesar $83,33 \%$, sedangkan pada tahun 2017 faktor resiko persalinan dengan lilitan tali pusat sebesar $28,57 \%$ dan tidaak terlilit tali pusat sebesar $71,42 \%$.

\section{PEMBAHASAN}

Asfiksia adalah suatu keadaan dimana bayi tidak dapat bernapas secara spontan dan teratur segera setelah lahir atau beberapa saat setelah lahir. Asfiksia terjadi karena terdapat gangguan pertukaran gas atau pengangkutan oksigen dari ibu ke janin. Gangguan ini dapat timbul pada masa kehamilan, persalinan atau segera setelah lahir. Asfiksia dapat mempengaruhi organ vital lainnya dan dapat mendorong terjadinya infeksi, kerusakan otak atau kematian.

Faktor Resiko Bayi: Hasil penelitian pada Tabel 2 menunjukkan bahwa sebagian besar sampel penelitian termasuk ke dalam kategori berat badan bayi berisiko rendah yaitu pada tahun 2016 sebanyak 10 kasus (83,33\%) dan pada tahun 2017 sebanyak 16 kasus $(76,19 \%)$.

Faktor Resiko Ibu: Hasil analisa penelitian (tabel 3) dapat dilihat bahwa pada tahun 2016 dari 12 bayi baru lahir yang menderita asfiksia, sebanyak 5 kasus $(41,67 \%)$ berdasarkan faktor ibu dengan risiko tinggi merupakan penyebab asfiksia, dan 7 kasus $(58,33 \%)$ merupakan risiko rendah. Sedangkan pada tahun 2017, dari 21 bayi baru lahir yang menderita asfiksia, sebanyak 10 kasus $(47,62 \%)$ berdasarkan faktor ibu dengan risiko tinggi merupakan penyebab asfiksia, dan 11 kasus (52,38\%) merupakan risiko rendah.

Faktor Resiko Persalinan : Hasil penelitian table 4 menunjukan bahwa pada tahun 2016 dari 12 bayi baru lahir yang menderita asfiksia, sebanyak 2 kasus 
$(16,67 \%)$ berdasarkan faktor risiko persalinan dengan lilitan tali pusat sebagai penyebab asfiksia, dan 10 kasus $(83,33 \%)$ merupakan faktor risiko persalinan tanpa lilitan tali pusat. Sedangkan pada tahun 2017, dari 21 bayi baru lahir yang menderita asfiksia, sebanyak 6 kasus $(28,57 \%)$ berdasarkan faktor risiko persalinan dengan lilitan tali pusat sebagai penyebab asfiksia, dan 15 kasus $(71,43 \%)$ merupakan faktor risiko persalinan tanpa lilitan tali pusat.

\section{KESIMPULAN}

1. Tidak ada pengaruh faktor risiko bayi dengan kejadian asfiksia

2. Tidak ada pengaruh faktor risiko ibu dengan kejadian asfiksia

3. Tidak ada pengaruh faktor risiko persalinan dengan kejadian asfiksia

\section{SARAN}

1. Bagi Tenaga Kesehatan/Puskesmas

Diharapkan tenaga kesehatan dapat menerapkan ilmu pengetahuan dalam tatanan praktik kebidanan yang berkembang seiring waktu, meningkatkan keterampilan khususnya dalam penanganan bayi dengan indikasi asfiksia dengan berbagai faktor yang mendasari.

2. Bagi Pendidikan

Dapat meningkatkan kualitas penyelenggaraan pendidikan bagi para mahasiswa dengan penyediaan prasarana dan sarana laboratorium yang mendukung peningkatan kemampuan mahasiswa dalam penanganan bayi dengan asfiksia.

3. Bagi Penulis Peneliti

Dapat melanjutkan penelitian lebih lanjut tentang kejadian asfiksia pada jenjang pendidikan yang lebih tinggi dengan melihat aspek / variable lain dan dengan uji statistik yang sesuai.

\section{DAFTAR PUSTAKA}

Ai Yeyeh dkk, 2013. Asuhan Kebidanan Kehamilan, Cet. I. Jakarta: CV. Trans Info Media

Bagus, I,G,M. 2008. Asuhan Kebidanan Persalinan. Jakarta

Departemen Kesehatan RI. 2008. Pencegahan dan Penatalaksanaan Asfiksia Neonatorum. Jakarta

Depaartemen Kesehatan RI. 2015. Asuhan Persalinan Normal. Jakarta

Desfauza, Evi. 2008. "Faktor-faktor yang mempengaruhi terjadinya asfiksia neonatorum pada bayi abru lahir yang dirawat di RSU Pirngadi Medan". Stikes Mitra Husada Medan

Ghai dkk, 2010. Pencegahan dan Penatalaksanaan Asfiksia Neonatorum. Helath Technology Assessment Indonesia Departemen Kesehatan Republik Indonesia.

Gilang dkk, 2011. Faktor-Faktor yang Berhubungan Dengan Kejadian Asfiksia Neonatorum di RSUD Tugurejo Semarang. Skripsi. Tidak Dipublikasikan

Jannah, 2013. Buku Asuhan Kebidanan Kehamilan. Yokyakarta; C.V Andi Offset.

JNPK-KR. 2012. Buku Saku Pelayanan Kesehatan Neonatal Esensial. Jakarta

Lee, et. Al. 2008. " Risk factors for Neonatal mortality Due to the birth Asphyxiain southern Nepal: A Prospective, Community-based Cohor Study".Amerika: american academiof pediatric.

Manuaba. 2008. IImu Kebidanan Penyakit Kandungan dan Kelauraga Berencana. Jakarta: EGC

Manuaba, 2010. IImu Kebidanan Penyakit Kandungan dan KB. Jakarta : Buku Kedokteran EGC.

Manuaba I.B.G, dkk, 2013. Ilmu Kebidanan,Penyakit Kandungan, dan KB Untuk Pendidikan Bidan . Edisi 2. Jakarta : EGC.

Mochtar R. 2008. "Sinopsis Obstetri", Jilid I, Edisi II. Jakarta: EGC.

Nasrawati. 2016. Hubungan Berat Bayi Lahir Rendah (BBLR) Dengan Kejadian Asfiksia Neonatorum di Rumah Sakit Umum Dewi Sartika Provinsi Sulawesi Tenggara. Akbid Konawe. 